\title{
Quantitative X-Ray Computed Tomography (CT) in Dementia of the Alzheimer Type (DAT)
}

\author{
J.S. Luxenberg, R.P. Friedland and S.I. Rapoport
}

\begin{abstract}
Dementia of the Alzheimer type (DAT) has proven to be difficult to diagnose using computerized X-ray tomography $(\mathrm{CT})$. To improve the identification of DAT with CT, several different quantitative approaches have been tried. Brain parenchymal density measurements and a variety of linear indices of ventricular size have failed to reliably separate DAT patients from age matched controls. Measures of ventricular volume improve discrimination, but overlap with controls persists. The inadequacy of a single CT study to diagnose DAT is clearly related to the overlap of brain atrophy in DAT and healthy aging, a finding which has also been noted in post-mortem studies. Estimating the rate of ventricular enlargement from quantitative measurements of ventricular size on successive CT scans may allow the physician to take advantage of the progressive nature of DAT, improving separation of DAT patients from healthy controls.
\end{abstract}

RÉSUMÉ: Tomographie quantitative à rayons $\mathbf{X}$ assistée par ordinateur dans la démence de type Alzheimer. Il s'est avéré difficile de diagnostiquer la démence de type Alzheimer (DTA) au moyen de la tomographie par rayons X assistée par ordinateur (TAO). Plusieurs approches quantitatives différentes ont été essayées dans le but d'améliorer l'identification de la DTA au moyen de la TAO. Il a été impossible de séparer de façon fiable les patients atteints de DTA de témoins appariés pour l'âge, au moyen de mesures de la densité du parenchyme du cerveau et d'index linéaires variés de la taille des ventricules. Les mesures de volumes ventriculaires améliorent la discrimination, mais il persiste un chevauchement avec les mesures des témoins. Le fait qu'un seul examen par TAO soit inadéquat pour poser le diagnostic de DTA est, de toute évidence, relié au chevauchement des mesures de l'atrophie du cerveau chez les patients atteints de DTA et les vieillards sains, une observation qui a également été notée dans les études effectuées en post-mortem. L'estimation de la vitesse d'agrandissement des ventricules à partir de mesures quantitatives de la taille des ventricules sur des TAO successives peut permettre au médecin de profiter de la nature progressive de la DTA pour améliorer la séparation des patients atteints de DTA des témoins normaux.

Can. J. Neurol. Sci. 1986; 13:570-572

Computerized X-ray transverse axial tomography (CT) of the brain was introduced in $1973^{\prime}$ and has subsequently found wide application in neurology. Progressive dementing illnesses have proven difficult to diagnose accurately in life, and soon after its introduction the CT technique was used to study dementia. ${ }^{2} \mathrm{CT}$ correlates strongly with pneumoencephalography, ${ }^{3}$ the invasive technique previously used to judge ventricular enlargement. In addition, $\mathrm{CT}$ is useful in demonstrating subdural hematomas, tumors, normal pressure hydrocephalus and other potentially treatable causes of the dementia syndrome. ${ }^{2} \mathrm{CT}$ also allows detection of clinically unsuspected infarction $s^{2}$ helpful in diagnosing multiinfarct dementia, ${ }^{4}$ the second most common form of dementing illness in the elderly. ${ }^{5}$ It was soon recognized, however, that the most common form of dementing illness, dementia of the Alzheimer type (DAT), ${ }^{5}$ shows changes on CT that overlap ${ }^{2}$ considerably with those in age matched control subjects. Takeda and Matsuzawa ${ }^{6}$ and Schwartz ${ }^{7}$ showed increased ventricular size with advanced age in healthy subjects, making the diagnosis of DAT on the basis of CT findings difficult in the old patient. Necropsy studies have shown that the enlargement of ventricles and loss of cortical gray matter and central white matter in DAT are variable and overlap ${ }^{8}$ with age matched controls. However, post-mortem studies of brain atrophy are difficult to quantitate and suffer from the variable effects of fixation on brain volume. ${ }^{8}$ Studies of the relationships of cortical atrophy in DAT to the behavioral features of the disease, and comparisons to age related atrophy are best performed with CT.

Several different approaches toward improved discrimination of DAT using CT have been attempted. The brain parenchymal density measurements in Hounsfield units (HU) reflect true tissue $\mathrm{X}$-ray attenuation. The density of gray matter and 
white matter, as well as the difference between the two tissue types, have been studied qualitatively ${ }^{9}$ and quantitatively ${ }^{9-11}$ in DAT. Loss of gray-white discrimination ${ }^{9}$ and decreased mean density" were shown, but in both studies the level measured was in part determined by the ventricular size, known to be often increased in DAT. The level of a particular CT slice in relation to the base of the skull influences the degree that the density values are artifactually elevated by the proximity to bone, the "beam hardening" effect. ${ }^{12}$ Controlling for position in the skull, Gado ${ }^{10}$ found no evidence of a loss of CT density in DAT.

In an attempt to improve discrimination between DAT and healthy aging, a variety ${ }^{2.13-18}$ of linear indices of ventricular size have been measured. In general, these techniques have not permitted adequate separation of patient groups, although in young patients with DAT, Albert ${ }^{18}$ was able to correctly assign $79 \%$ of patients and age matched controls. Measures of "cortical atrophy" have been attempted, including width of the largest sulci $i^{2,19}$ and the outline of the perimeter of the brain traced, then standardized to cranial size. ${ }^{20.21}$ Again, these measures have not proven valuable in differentiating DAT from healthy aging and other degenerative dementias.

The irregular shape of the cerebral ventricles contributes to the difficulty in reliably measuring ventricular size. By summing the ventricular area on serial CT slices, and multiplying the sum by the interslice distance, ventricular volumes can be calculated. ${ }^{22}$ Whereas thin slices would be expected to maximize the accuracy of such an integration, the loss of planar resolution with a given radiation dose and thinner slices limit the use of this volumetric technique to slices that are $8-10 \mathrm{~mm}$ thick. ${ }^{6,7.22,23}$ Computer software for semi-automated volumetric analysis of brain atrophy have been described. ${ }^{24.25}$ Although volumetric measurements of ventricular size have improved group differences ${ }^{22}$ between DAT and controls, considerable overlap persists, ${ }^{22,26}$ particularly in patients with mild DAT. ${ }^{26}$

The inadequacy of a single $\mathrm{CT}$ scan, ${ }^{27,28}$ no matter what measure of brain atrophy is used, to diagnose DAT is clearly related to the overlap of brain atrophy in DAT and healthy aging. A longitudinal approach, however, can take advantage of the progressive nature of DAT. Gado ${ }^{29}$ showed enlargement of linear indices of ventricular size in 21 patients with mild DAT over approximately one year of follow-up. In a similar study of healthy aging, ${ }^{22}$ volumetric measures were found to be more sensitive than linear indices in showing ventricular enlargement. Brinkman ${ }^{30}$ et al showed that linear indices of ventricular size showed more rapid enlargement in 4/5 DAT patients than the rate of control subjects calculated from a cross-sectional study. Our laboratory ${ }^{31}$ recently has found that volumetric measures of lateral ventricular enlargement completely separated a group of 12 patients with DAT from 12 healthy age-matched controls. Third ventricular enlargement did not successfully separate these groups, possibly because of the difficulty measuring the relatively small volume of the third ventricle with CT. ${ }^{31}$

The utility of serial CT scanning in diagnosing DAT needs to be confirmed with larger studies, incorporating patients with mild and/or early disease where diagnosis is most difficult. Specificity must be explored by studying other dementing illnesses that can be confused with DAT. To insure maximal accuracy, careful attention must be paid to positioning the patient in the scanner in a standardized, easily reproducible manner. Investigators must be trained to maximize intrarater and interrater reliability of measurements.
The apparent size of an anatomic structure in a CT image can vary depending on the display settings determined by the viewing physician. ${ }^{32.33}$ Methods of quantitative analysis of CT images often require the analyst to outline regions of interest; ${ }^{29}$ the viewing window must be standardized ${ }^{7}$ to insure consistency across serial scans. The apparent size of objects is also related to slice thickness (collimator width). ${ }^{33}$ The technique used for CT scanning should therefore be the same for each scan in a serial study. Ideally, the same CT scanner should be used for each scan, and careful daily calibration should be used with phantoms of several X-ray densities.

The advent of magnetic resonance imaging (MRI) may provide a useful method of serial scanning without radiation exposure. MRI measures of cerebral atrophy correlate strongly with CT measures. ${ }^{34,35}$ The thinner slice thickness theoretically obtainable with MRI will minimize partial voluming artifacts. The accuracy of area measurements using current commercially available CT and MRI has been compared by $\mathrm{Zhu}^{36}$ et al. However, present MRI scanning is often less accurate than CT in measuring the area of phantoms. ${ }^{36}$ Additional problems with the use of MRI for quantitative studies include the difficulty of calibration, the length of time necessary for the patient to hold still for the scan, and the difficulty of reproducibly positioning the patient in the scanner.

\section{REFERENCES}

1. Hounsfield GN. Computerized transverse axial scanning (tomography): Part 1. Description of system. Br J Radiol 1973; 46: 1016-1022.

2. Huckman MS, Fox J, Topel J. The validity of criteria for the evaluation of cerebral atrophy by computed tomography. Radiol 1975; 116: 85-92.

3. Synek V, Reuben JR, Du Boulay GH. Comparing Evan's index and computerized axial tomography in assessing relationship of ventricular size to brain size. Neurol 1976; 26: 231-233.

4. Tomlinson BE, Blessed G, Roth M. Observations on the brains of demented old people. J Neurol Sci 1970; 11: 205-242.

5. Cummings JL, Benson DF. Dementia. A Clinical Approach. Boston, Butterworth Publishers, 1983.

6. Takeda S, Matsuzawa T. Brain atrophy during aging. A quantitative study using computed tomography. J Am Geriatr Soc 1984; 32: $520-524$.

7. Schwartz M, Creasey H, Grady CL, et al. Computed tomographic analysis of brain morphometrics in 30 healthy men, aged 21 to 81 years. Ann Neurol 1985; 17: 146-157.

8. Hubbard BM, Anderson JM. A quantitative study of cerebral atrophy in old age and senile dementia. J Neurol Sci 1981; 50: 135-145.

9. George AE, de Leon MJ, Ferris SH, et al. Parenchymal CT correlates of senile dementia [Alzheimer disease]: loss of graywhite matter discriminability. AJNR 1981; 2: 205-213.

10. Gado M, Patel J, Hughes CP, et al. Brain atrophy in dementia judged by CT scan ranking. AJNR 1983; $4: 499-500$.

11. Albert M, Naeser MA, Levine HL, et al. CT density numbers in patients with senile dementia of the Alzheimer's type. Arch Neurol 1984; 41: 1264-1269.

12. Gado $M$, Phelps $M$. The peripheral zone of increased density in cranial computed tomography. Radiol 1975; 117: 71-74.

13. Hahn FJ, Rim K, Schapiro RL. A quantitative analysis of ventricular size on computed tomographic scans. Computed Axial Tomogr 1977; 1: 121-125.

14. Jacoby RJ, Levy R, Dawson JM. Computed tomography in the elderly: 1. The normal population. Brit J Psychiat 1980; 136: 249-255.

15. Brinkman SD, Sarwar M, Levin HS, et al. Qualitative indexes of computed tomography in dementia and normal aging. Radiol 1981; 138: 89-92. 
16. Soininen H, Puranen M, Riekkinen PJ. Computed tomography findings in senile dementia and normal aging. J Neurol Neurosurg Psychiat 1982; 45: 50-54.

17. Arai $\mathrm{H}$, Kobayashi $\mathrm{K}$, Ikeda $\mathrm{K}$, et al. A computed tomography study of Alzheimer's disease. J Neurol 1983; 229: 69-77.

18. Albert M, Naeser MA, Levine HL, et al. Ventricular size in patients with presenile dementia of the Alzheimer's type. Arch Neurol 1984; 41: 1258-1263.

19. Roberts MA, Caird FI. Computerized tomography and intellectual impairment in the elderly. J Neurol Neurosurg Psychiat 1976; 39: 986-989.

20. Zatz Jr. LM, Jernigan TL, Ahumada AJ. White matter changes in cerebral computed tomography related to aging. J Comp Assist Tomogr 1982; 6: 19-23.

21. Turkheimer E, Munro Cullum C, Hubler DW, et al. Quantifying cortical atrophy. J Neurol Neurosurg Psychiat 1984;47: 1314-1318.

22. Gado M, Hughes CP, Danziger W, et al. Volumetric measurements of the cerebrospinal fluid spaces in demented patients and controls. Radiol 1982; 144: 535-538.

23. George AE, de Leon MJ, Rosenbloom S, et al. Ventricular volume and cognitive deficit: a computed tomographic study. Radiol $1983 ; 149: 493-498$.

24. Sundsten JW, Prothero JW. Three-dimensional reconstruction from serial sections: ii. A microcomputer-based facility for rapid data collection. Anat Rec 1983; 207; 665-671.

25. DeLeo JM, Schwartz M, Creasey H, et al. Computer-assisted categorization of brain computerized tomography pixels into cerebrospinal fluid, white matter, and gray matter. Comp Biomed Res 1985; 18: 79-88.

26. Creasey H, Schwartz M, Frederickson H, et al. Quantitative computed tomography in dementia of the Alzheimer type. Neurol in press.
27. Bird JM. Computerized tomography, atrophy and dementia. A review. Prog Neurobiol 1982; 19: 91-115.

28. McGeer PL. Brain imaging in Alzheimer's disease. Brit Med Bull 1986; 42: 24-28.

29. Gado M, Hughes CP, Danziger W, et al. Aging, dementia, and brain atrophy: a longitudinal computed tomographic study. AJNR $1983 ; 4: 699-702$.

30. Brinkman SD, Largen Jr JW. Changes in brain ventricular size with repeated cat scans in suspected Alzheimer's disease. Am J Psych 1984; 141: 81-83.

31. Luxenberg J, Creasey $\mathrm{H}$, Haxby $\mathrm{J}$, et al. The rate of ventricular enlargement in dementia of the Alzheimer type correlates with rate of neuropsychological deterioration. [Abstract] J Nucl Med 1986; $27: 1024$.

32. Koehler PR, Anderson RE, Baxter B. The effect of computed tomography viewer controls on anatomical measurements. Radiol 1979; 130: 189-194.

33. Baxter BS, Sorenson JA. Factors affecting the measurement of size and CT number in computed tomography. Invest Radiol 1981; 16: 337-341.

34. McGeer PL, Kamo H, Harrop R, et al. Positron emission tomography in patients with clinically diagnosed Alzheimer's disease. Can Med Assoc J 1986; 134: 597-607.

35. Erkinjuntti T, Sipponen JT, Iivanainen M, et al. Cerebral NMR and CT imaging in dementia. J Comp Assist Tomogr 1984; 8: 614-618.

36. Zhu XP, Checkley DR, Hickey DS, et al. Accuracy of area measurements made from MRI images compared with computed tomography. J Comp Assist Tomogr 1986; 10: 96-102. 